\title{
EVALUASI KESESUAIAN DOSIS INSULIN PADA PASIEN PROLANIS DI RUMAH SAKIT X TAHUN 2019
}

\section{EVALUATION OF THE SUITABILITY OF INSULIN DOSES IN PROLANIS BASED ON THE LITERATURES AT RS X 2019}

\author{
Nadliyatul Umah', Ainun Muthoharoh ${ }^{2}$, Wulan Agustin Ningrum ${ }^{3}$, Wirasti ${ }^{4}$ \\ ${ }^{1}$ Farmasi, Fakultas Ilmu Kesehatan, Universitas Muhammadiyah Pekajangan Pekalongan \\ Jl. Raya Ambokembang No.08 Pekajangan-Pekalongan \\ Email : Nadliyatul.ummah@yahoo.com / 085228004919
}

Submitted : 14 Agustus 2020 Reviewes : 28 Agustus 2020 Accepted : 20 September 2020

\begin{abstract}
ABSTRAK
Kasus penyakit diabetes melitus di Kabupaten Batang pada urutan dua setelah penyakit hipertensi. Prevalensi penyakit diabetes melitus sebanyak 17,53\%. Salah satu terapi pada pasien prolanis adalah insulin. Kesesuaian dosis insulin sangat diperlukan untuk memperoleh hasil terapi yang diharapkan. Tujuan penelitian ini adalah untuk mengetahui gambaran kesesuaian dosis insulin pada pasien prolanis. Metode penelitian adalah observasional dengan pengambilan data retrospektif. Data diambil dari rekam medik pasien diabetes melitus. Kriteria insklusi yaitu data rekam medik pasien diabetes melitus peserta prolanis yang menggunakan insulin. Kriteria eksklusi yaitu rekam medik yang tidak lengkap. Evaluasi kesesuaian dosis menggunakan literatur dengan jumlah sampel 85 rekam medik yang diambil, pada tahun 2019 dibagian rawat jalan. Hasil dari karakteritik prolanis di RS X yaitu pada kelompok usia 60-74 tahun (lansia) sebanyak 49,4\%, jenis kelamin lebih banyak laki-laki yaitu 52,9\%, hasil diagnosa pasien prolanis yang paling banyak yaitu diabetes militus komplikasi 52,9\% dan jenis insulin yang sering diberikan untuk pasien prolanis yaitu novomix 30 flexpen sebanyak 84,7\%. Hasil dari evaluasi kesesuaian dosis berdasarkan literatur Standard of Medical Care In Diabetes 2018, Drug Information Handbook 19th Edition (Lacy dkk, 2010), The Renal Drug Handbook, MIMS edisi 17, ISO volume 51 yang sesuai sebanyak 100\%, kemudian berdasarkan guidelineComparison of 2 intravenous insulin protocols : glycemia variability in critically ill patientsyang sesuai sebanyak $34,1 \%$ dan guidelineUpdate On Management Of In-hospital Hyperglycemiayang sesuai sebanyak $27,1 \%$.
\end{abstract}

Kata kunci : Pasien Diabetes Melitus, Prolanis, Insulin, Kesesuaian Dosis.

\begin{abstract}
Diabetes mellitus in Batang District is in second place after hypertension. The prevalence of diabetes mellitus was $17.53 \%$. One of the therapies in prolanis patients is insulin. Appropriateness of insulin doses is needed to obtain the expected therapeutic results. The purpose of this study was to describe the suitability of insulin doses in prolanis patients. The research method is observational with retrospective data collection. Data were taken from medical records of diabetes mellitus patients. The inclusion criteria were medical records of patients with diabetes mellitus participants who used insulin. The exclusion criteria were incomplete medical records. Evaluation of dosage suitability using literature with a sample size of 85 medical records taken, in 2019 in the outpatient section. The results of the prolanis characteristics at X Hospital were in the 60-74 years age group (elderly) as much as $49.4 \%$, more sex was male, namely $52.9 \%$, the diagnosis result of the most prolanic patients was diabetes mellitus complications 52, 9\% and the type of insulin that is often given to prolanis patients is novomix 30 flexpen as much as $84.7 \%$. The results of the evaluation of dose
\end{abstract}


suitability based on the literature on Medical Care Standards in Diabetes 2018, Handbook of Drug Information Edition 19 (Lacy et al, 2010), The Renal Drug Handbook, MIMS 17th edition, ISO volume 51 are $100 \%$, then based on insulin protocol guidelines intravenous: variability of glycemia in critically ill patients accordingly was $34.1 \%$ and hospitalized Hyperglycemic Management Update guidelines was $27.1 \%$.

Keywords: Diabetes Mellitus Patients, Prolanis, Insulin, Dosage Appropriateness.

\section{Penulis Korespondensi :}

Nadliyatul Umah

Universitas Muhammadiyah Pekajangan Pekalongan

Jl. Raya Ambokembang No.08 Pekajangan-Pekalongan

Email : Nadliyatul.ummah@yahoo.com 085228004919

\section{PENDAHULUAN}

Diabetes melitus merupakan suatu gangguan penyakit kronis karena kekurangan insulin dan tidak dapat memproduksi insulin dengan normal. Apabila tubuh mengalami kekurangan insulin maka gula darah akan meningkat (Jay \& Rahardja, 2015). WHO (2015); menyebutkan bahwa jumlah penderita penyakit diabetes mellitus di dunia pada tahun 2015 mencapai 415 juta orang. Menurut data RISKESDAS (2013), prevalensi penyakit diabetes militus di Indonesia untuk usia di atas 15 tahun sebanyak 2,1\%.

Data Depkes RI (2012), menunjukan rata-rata kasus penderita diabetes mellitus di Jawa Tengah sebanyak 4.216 kasus. Hasil dari Dinas Kesehatan Kabupaten Batang, pada tahun 2017 jumlah masyarakat yang mempunyai riwayat diabetes mellitus sebanyak 17,53\%. Penelitian ini dilakukan di Rumah Sakit X, kesesuaian dosis insulin perlu diperhatikan, apabila dosis insulin tidak sesuai mengakibatkan hiperglikemik tidak terkontrol. Prolanis merupakan suatu sistem pelayanan kesehatan dan pendekatan proaktif yang melibatkan peserta, fasilitas kesehatan, dan BPJS dalam rangka pemeliharaan kesehatan agar mencapai kualitas hidup yang optimal dan biaya yang efektif dan efisien. Dosis insulin dengan prolanis ada kaitannya yaitu pada umur, jenis kelamin dan BB pasien.

\section{METODE PENELITIAN}

Penelitian ini termasuk penelitian non eksperimental yang bersifat deskriptif retrospekif yang di analisis menggunakan univariat. Retrospektif yaitu pengambilan data pada tahun lalu (Notoatmodjo, 2012).

\section{Alat dan Bahan}

Alat yang digunakan pada penelitian ini yaitu lembar evaluasi kesesuaian dosis insulin dan literatur Standard of Medical Care In Diabetes 2018, Drug Information Handbook 19th Edition (Lacy dkk, 2010), The Renal Drug Handbook, MIMS edisi 17, ISO volume 51 dan berdasarkan guideline Comparison of 2 intravenous insulin protocols : glycemia variability in critically ill patientsdan guideline Update On Management Of Inhospital Hyperglycemia. Ketidak patuhan dapat dinilai dari rutin atau tidak pasien dalam menjalani pengobatan. Bahan yang digunakan dalam penelitian ini meliputi data rekam medik pasien tahun 2019.

\section{Jalannya Penelitian}

1. Penentuan Sampel Penelitian

Dalam tahap ini didapatkan populasinya yaitu data rekam medikpasien yang didiagnosa diabetes melitus yang menjalani prolanis di RS X Kabupaten Batang pada tahun 2019 dan menggunakan obat insulin. Sampel yang digunakan sebanyak 81 sampel yang didapatkan dari $10 \%$ dari jumlah sampel yaitu 802 . Menurut Notoadmodjo 
(2011), menyatakan bahwa pada kesalahan acak dapat ditambahkan sebesar 5\%, $10 \%$ atau $15 \%$. Semakin besar tingkat kesalahannya maka semakin kecil sampel, dan sebaliknya semakin kecil tinkat kesalahannya maka semakin besar jumlah sampel yang diperoleh. Pada penelitian ini probality kesalahan yang diambil $<5 \%$, sehingga jumlah sampel yang diambil sebesar 5\% menjadi total sampel 85 . Pengambilan sampel berdasarkan kriteria inklusi. Kriteria inklusi yaitu data rekam medik responden yang menjalani prolanis dan menggunakan insulin. Kriteria eklusi yaitu rekam medik yang tidak lengkap.

2. Pengumpulan Data

Penelitian ini dilakukan berdasarkan data dari rekam medik pasien yang menjalani prolanis dan menggunakan insulin. Data yang diambil untuk penelitian yaitu umur, jenis kelamin, diagnosa pasien, dosis, jenis insulin dan kadar gula darah selama 3 bulan.

\section{Analisis Data}

Analisis data untuk penelitian ini menggunakan analisis univariat yang bertujuan untuk analisis setiap variabel yang diteliti dalam bentuk persentase (\%).

\section{HASIL DAN PEMBAHASAN}

Di RS X belum pernah dilakukan penelitian tentang evaluasi kesesuaian dosis insulin pada prolanis. Penelitian ini dilakukan di RS X Kabupaten Batang pada bulan April-Mei 2020. Tujuan dari penelitian ini untuk memperoleh gambaran tentang evaluasi kesesuaian dosis insulin pada prolanis selama menjalani perawatan diabetes melitus. Penelitian ini termasuk penelitian non eksperimental yang bersifat deskriptif retrospekif yang di analisis menggunakan univariat. Hasil dari studi pendahuluan di RS X jumlah sampel pasien prolanis yang menggunakan insulin pada tahun 2019 sebanyak 802 pasien. Sampel yang diteliti sebanyak 85 rekam medik. Data yang didapatkan kemudian diamati dan dikaji dari kelengkapan rekam medik, kesesuaian dosis insulin dan karakteristik dari prolanis. Pada saat mengevaluasi kesesuaian dosis insulin berdasarkan literatur Standard of Medical Care In Diabetes 2018, Drug Information Handbook 19th Edition (Lacy dkk, 2010), The Renal Drug Handbook, MIMS edisi 17, ISO volume 51 dan guidelineComparison of 2 intravenous insulin protocols : glycemia variability in critically ill patients dan guidelineUpdate On Management Of In-hospital Hyperglycemia.

\section{A. Karakteristik Prolanis}

Karakteristik responden dilihat dari data rekam medik pasien prolanis yang terdiri dari usia, jenis kelamin, diagnosa dan jenis insulin. Metode yang digunakan untuk mengevaluasi karakteristik prolanis yaitu deskriptif retrospektif yang dianalisis menggunakan univariat.

1. Usia

Usia yaitu lamanya waktu hidup seseorang atau lamanya keberadaan seseorang yang di ukur dalam satuan waktu (WHO, 2011). Hasil data rekam medik usia responden yang menggunakan insulin bisa dilihat padaTabel I.

Tabel I. Usia Pasien Prolanis

\begin{tabular}{ccc}
\hline Usia (tahun)* & Jumlah (n) & Persentase (\%) \\
\hline 26-35 (dewasa muda) & 1 & 1,2 \\
36-45 (dewasa akhir) & 5 & 5,9 \\
46-59 (pertengahan) & 36 & 42,4 \\
60-74 (lansia) & 42 & 49,4
\end{tabular}




\begin{tabular}{ccc}
\hline $75-90$ (lanjut usia tua) & 1 & 1,2 \\
\hline Total & 85 & 100
\end{tabular}

*Rentang usia berdasarkan WHO (2011)

Tabel I Jumlah responden yang paling banyak dari 85 sampel yang diteliti pada kelompok usia 60-74 tahun dengan persentase 49,4\%. Resiko terjadinya peningkatan glukosa seiring dengan tambahnya usia. Salah satu faktor risiko dari diabetes melitus tipe 2 terjadi pada usia $>45$ tahun. Diabetes melitus sering ditemukan pada lanjut usia dikarenakan seseorang akan mengalami penurunan baik secara fisik maupun psikis, seperti sistem endokrin mengakibatkan sel beta pankreas menurun pada saat memproduksi insulin (Kurnianto, 2015).

2. Jenis Kelamin

Jenis kelamin yaitu sesuatu yang membedakan antara laki-laki dengan perempuan. Data jenis kelamin pada penelitian ini dapat dilihat pada Tabel II.

Tabel II. Jenis kelamin

\begin{tabular}{ccc}
\hline Jenis Kelamin & Jumlah (n) & Persentase (\%) \\
\hline Perempuan & 40 & 47,1 \\
Laki-laki & 45 & 52,9 \\
\hline Total & 85 & 100
\end{tabular}

Pada Tabel II jumlah responden yang berjenis kelamin laki- laki sebanyak 52,9 $\%$ dan jumlah perempuan sebanyak $47,1 \%$. Penelitian ini lebih banyak laki-laki karena gaya hidup yang tidak sehat dapat mempengaruhi peningkatan frekuensi diabetes melitus tipe 2. Kemungkinan laki-laki pada merokok sehingga menimbulkan diabetes melitus. Nikotin yang terdapat pada asap rokok mempunyai pengaruh terhadap insulin seperti menurunnya pelepasan insulin akibat aktivasi hormon ketokolamin, pengaruh negatif terhadap kerja insulin dan terjadi gangguan pada sel $\beta$ pankreas sehingga menyebabkan resisten insulin (Sepmawati, 2015).

3. Diagnosa

Diagnosa pada responden dibedakan menjadi DMT2 tanpa komplikasi, DMT2 komplikasi dan DMT2 yang disertai penyakit penyerta. Hasil dari diagnosa tersebut dapat dilihat pada Tabel III.

Tabel III. Diagnosa responden

\begin{tabular}{ccc}
\hline Diagnosa & Jumlah (n) & Persentase (\%) \\
\hline DMT 2 komplikasi & 45 & 52,9 \\
DMT 2 tanpa komplikasi & 35 & 41,2 \\
DMT 2 dengan penyakit \\
penyerta
\end{tabular}

Keterangan: DMT2 =Diabetes melitus tipe 2

Pada Tabel III penyakit diabetes melitus yang disertai komplikasi sebanyak $52,9 \%$, diabetes melitus yang tidak disertai komplikasi sebanyak $41,2 \%$ dan diabetes melitus yang disertai penyakit penyerta sebanyak 5,9\%. Penyebab terjadinya komplikasi karena kadar gula darah yang tidak terkontrol sehingga mengakibatkan 
kerusakan pada organ lainnya (Perkeni, 2011). Menurut Hongdiyanto (2013), jumlah pasien yang mengalami komplikasi sebanyak $75 \%$. Kadar gula darah yang tinggi dan terus menerus dapat menyebabkan suatu keadaan gangguan pada berbagai organ tubuh. Akibat keracunan yang menetap ini, timbul perubahan-perubahan pada organorgan tubuh sehingga timbul berbagai komplikasi. Jumlah responden yang mempunyai penyakit penyerta sebanyak 5 responden. Penyakit penyerta dapat dilihat pada Tabel IV.

Tabel IV. Penyakit penyerta diabetes melitus tipe 2 pada responden

$\begin{array}{lll}\text { Penyakit penyerta DMT2 } & \text { Jumlah (n) } & \text { Persentase (\%) }\end{array}$

\begin{tabular}{ccc}
\hline DMT 2 + dyspepsia & 3 & 60,0 \\
DMT2 + PPOK & 1 & 20,0 \\
DMT 2 + pneumonia & 1 & 20,0 \\
\hline Total & 5 & 100
\end{tabular}

Pada Tabel IV penyakit penyerta pada diabetes melitus tipe 2 terdiri dari dyspepsia sebanyak $60,0 \%$. Pada penelitian yang pernah dilakukan oleh Purnamasari (2017), jumlah pasien yang mengalami dyspepsia sebanyak 71\%. Dispepsia merupakan penyakit penyerta yang disebabkan oleh kanker lambung, kegagalan terapi, riwayat ulkus peptikum, penggunaaan obat NSAID jangka panjang dan alkohol kronis. Perokok pasif dan aktif bisa menyebabkan penurunan tekanan spingter esofagus bagian bawah sehingga menyebabkan refluk gastroesofagus dan mengganggu pengosongan pada lambung (Purnamasari, 2017). Penyakit komplikasi terdapat 45 dari 85 responden. Penyakit komplikasi pada diabetes melitus tipe 2 dapat dilihat pada Tabel V.

Tabel V. Penyakit komplikasidiabetes melitus tipe 2 pada responden

\begin{tabular}{rcc}
\hline Penyakit komplikasi DMT2 & Jumlah (n) & Persentase (\%) \\
\hline DMT 2 + disliphidemia & 1 & 2,2 \\
DMT 2 + hipertensi & 15 & 33,3 \\
DMT 2 + hipertensi + TBC & 1 & 2,2 \\
DMT2 + TBC & 4 & 8,9 \\
DMT 2 + CHF & 10 & 22,2 \\
DMT 2 + CHF+ IHD & 1 & 2,2 \\
DMT 2 + jantung + hipertensi & 1 & 2,2 \\
DMT 2 + jantung + stroke & 1 & 2,2 \\
DMT 2 + stroke & 1 & 2,2 \\
DMT 2 + CKD & 4 & 8,9 \\
DMT 2 + CKD + TBC & 1 & 2,2 \\
\hline
\end{tabular}




\begin{tabular}{ccc}
\hline DMT 2 + neuropati perifer & 5 & 11,1 \\
\hline Total & 45 & 100
\end{tabular}

Pada Tabel V penyakit komplikasi pada diabetes melitus yang paling banyak yaitu pada penyakit hipertensi sebanyak $33,3 \%$. Penyakit diabetes melitus tipe 2 dengan kadar gula tinggi dapat merusak sistem organ didalam tubuh dan membentuk aterosklerosis, hal tersebut dapat mengakibatkan arteri menjadi sempit dan tidak dapat mengembang sehingga mengakibatkan hipertensi (Hongdiyanto, 2013).

4. Jenis Insulin

Jenis insulin yang digunakan di RS X ada 3 macam yaitu novomix 30 flexpen, novorapid dan ezelin. Jenis insulin yang digunakan oleh RS X dapat dilihat pada Tabel VI.

Tabel VI. Jenis insulin

\begin{tabular}{ccc}
\hline Jenis Insulin & Jumlah (n) & Persentase (\%) \\
\hline Novomix 30 flexpen & 72 & 84,7 \\
Novorapid & 5 & 5,9 \\
Ezelin & 6 & 7,1 \\
Ezelin + Novorapid & 2 & 2,4 \\
\hline Total & 85 & 100
\end{tabular}

Pada Tabel VI jumlah responden yang paling banyak menggunakan jenis insulin novomix 30 flexpen yaitu 84,7\%. Dalam memilih insulin ditentukan oleh GDP, GD2JPP dan HbA1c. Novomix 30 flexpen termasuk dalam insulin premixed. Keunggulan penggunaan insulin premixed yaitu mengurangi jumlah penyuntikan dalam sehari dan meningkatkan kepatuhan pasien. Kandungan dari novomix yaitu insulin aspart 30\% dan protaminated insulin aspart 70\% (Inayah, 2014). Kandungan dari novorapid yaitu insulin aspart. Novorapid merupakan insulin jenis kerja cepat. Komposisi dari insulin ezelin yaitu insulin glargine. Pada insulin ezelin termasuk dalam insulin kerja panjang (Almasdy, 2015).

\section{B. Evaluasi Kesesuaian Dosis}

Evaluasi kesesuaian dosis yaitu proses menilai kesesuaian dosis apakah sudah tepat atau belum. Kriteria kesesuaian dosis dilihat dari kesesuaian dalam pemberian dosis yang diberikan. Evaluasi kesesuaian dosis insulin berdasarkan literatur dapat dilihat pada Tabel IX.

Tabel IX. Evaluasi kesesuaian dosis insulin

\begin{tabular}{ccccccccccc}
\hline $\begin{array}{c}\text { Kesesuaian } \\
\text { dosis }\end{array}$ & \multicolumn{2}{c}{$\mathbf{A}$} & \multicolumn{3}{c}{$\mathbf{B}$} & \multicolumn{2}{c}{$\mathbf{C}$} & $\mathbf{D}$ & \multicolumn{2}{c}{$\mathbf{E}$} \\
\cline { 2 - 11 } & $\mathbf{N}$ & $\mathbf{\%}$ & $\mathbf{N}$ & $\mathbf{\%}$ & $\mathbf{N}$ & $\mathbf{\%}$ & $\mathbf{N}$ & $\mathbf{\%}$ & $\mathbf{N}$ & $\mathbf{\%}$ \\
\hline Sesuai & 85 & 100,0 & 85 & 100,0 & 85 & 100,0 & 85 & 100,0 & 85 & 100,0 \\
Tidak sesuai & 0 & 0 & 0 & 0 & 0 & 0 & 0 & 0 & 0 & 0 \\
\hline Total & 85 & 100 & 85 & 100 & 85 & 100 & 85 & 100 & 85 & 100
\end{tabular}

Keterangan : A = Standard of Medical Care In Diabetes 2018

B = Drug Information Handbook 19th Edition (Lacy dkk, 2010) 


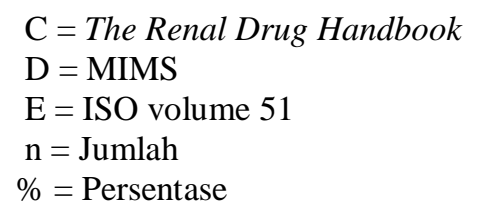

Pada Tabel IX jumlah responden yang sesuai dosis menurut literatur Standard of Medical Care In Diabetes 2018 sebanyak 100\%. Pada literatur Standard of Medical Care In Diabetes 2018 dosis pada insulin novomix dan novorapid yaitu dosis berdasarkan individual, sehingga dosis sesuai dengan kondisi tubuh. Pada insulin ezelin dosis awal 10 unit/hari atau 0,1-0,2 unit/kg/hari dan bersifat individual.

Jumlah responden yang sesuai dosis berdasarkan literatur Drug Information Handbook 19th Edition (Lacy dkk, 2010) yang sesuai dosis sebanyak 100\%. Literatur Drug Information Handbook 19th Edition (Lacy dkk, 2010) dosis pada novomix dan novorapid yaitu dosis bersifat individu. Pada insulin ezelin yaitu dosis awal 10 unit/hari dan dosis bersifat individual.

Jumlah yang sesuai dosis berdasarkan literatur The Renal Drug Handbook sebanyak 100\%. Dilihat dari literatur Renal Drug Handbook dosis pada insulin novomix, novorapid dan ezelin yaitu varibel atau dosis bersifat individu.

Jumlah responden yang sesuai dosis berdasarkan MIMS sebanyak 100\%. Dilihat dari literatur MIMS dosis pada insulin novomix yaitu Dosis subkutan bersifat individual, dosis awal yang dianjurkan $6 \mathrm{U}$ pada saat makan pagi \& $6 \mathrm{U}$ pada saat malam atau $1 \mathrm{x}$ perhari dengan dosis $12 \mathrm{U}$ pada saat makan malam. Dosis pada insulin novorapid yaitu dosis bersifat individual dan diberikan secara subkutan. Dosis lazim 0,5-1 U/kg BB/hari. Pada insulin ezelin dosisnya yaitu bersifat dosis bersifat individual.

Responden yang sesuai dosis insulin berdasarkan ISO volume 51 didapatkan hasil sebanyak $100 \%$. Dilihat dari literature ISO volume 51 dosis pada novomix yaitu dosis bersifat individual, dosis awal yang direkomendasikan adalah $6 \mathrm{U}$ pada malam hari $12 \mathrm{U}$ pada malam hari. Jika dosis sudah mencapai $30 \mathrm{U} / \mathrm{hari}$ maka direkomendasikan untuk membaginya menjadi 2 dosis yang sama pada pagi dan malam hari. Pada insulin novorapid dosisnya yaitu dosis bersifat individual. Pada rejimen basal-bolus, 50-70\% kebutuhan insulin 0,5-1 U/kg BB/hari dapat dipenuhi oleh novorapid dan sisanya dipenuhi insulin kerja panjang. Pada insulin ezelin dosisnya yaitu bersifat individual.

Ketepatan dosis perlu dilakukan agar mencapai terapi yang diinginkan dan tidak menimbulkan toksisitas. Dalam pemberian dosis dalam terapi diabetes melitus tipe 2 harus mempertimbangkan kondisi dari keadaan fungsi organ tubuh sehingga berpengaruh dalam pemberian dosis insulin (Samoh, 2016). Evaluasi kesesuaian dosis berdasarkan guideline 1 dan guideline 2 dapat dilihat pada Tabel $\mathrm{X}$.

Tabel X. Evaluasi kesesuaian dosis insulin

\begin{tabular}{ccccc}
\hline \multirow{2}{*}{ Kesesuaian dosis } & \multicolumn{2}{c}{ Guideline 1* } & \multicolumn{2}{c}{ Guideline 2* } \\
\cline { 2 - 5 } & $\mathbf{N}$ & $\mathbf{N}$ & $\mathbf{N}$ & $\%$ \\
\hline Sesuai & 29 & 34,1 & 23 & 27,1 \\
Tidak sesuai & 56 & 65,9 & 62 & 72,9 \\
\hline Total & 85 & 100 & 85 & 100 \\
\hline
\end{tabular}


*Keterangan : Guideline $1=$ Comparison of 2 intravenous insulin protocols : glycemia variability in critically ill patients

Guideline 2 = Update On Management Of In-hospital Hyperglycemia

Pada Tabel $\mathrm{X}$ jumlah responden yang sesuai dengan guideline 1 sebanyak $34,1 \%$ sedangkan jumlah responden yang tidak sesuai dengan guideline 1 sebanyak $65,9 \%$. Kemungkinan tidak sesuai dikarenakan penyakit diabetes melitus cukup kronis sehingga pemberiannya lebih tinggi dari guideline 1. Pada guideline 1 untuk mengevaluasi kesesuian dosis insulin berdasarkan skala Comparison of 2 intravenous insulin protocols : glycemia variability in critically ill patients dapat dilihat pada Tabel XI.

Tabel XI.Skala insulin

\begin{tabular}{ccccccc}
\hline $\begin{array}{c}\text { Kadar gula } \\
\text { darah }\end{array}$ & \multicolumn{6}{c}{ Guideline 1* } \\
\cline { 2 - 6 } Skala insulin \\
\hline $61-119$ & 0 & 0,5 & - & - & - & - \\
$120-149$ & 0 & 0,5 & 1,5 & 2 & 3 & - \\
$150-179$ & 0,5 & 1 & 2 & 3 & 4 & 5 \\
$180-209$ & 1 & 1,5 & 3 & 4 & 6 & 8 \\
$210-239$ & 1,5 & 2 & 4 & 6 & 9 & 12 \\
$240-269$ & 2 & 3 & 5 & 8 & 12 & 16 \\
$270-299$ & 3 & 4 & 6 & 9 & 16 & 22 \\
$300-349$ & 4 & 5 & 8 & 12 & 20 & 28 \\
$350-400$ & 5 & 6 & 10 & 16 & 24 & 36 \\
$>400$ & 6 & 7 & 12 & 20 & 30 & 44 \\
\hline
\end{tabular}

*Comparison of 2 intravenous insulin protocols : glycemia variability in critically ill patients

Pada guideline 2 jumlah responden yang sesuai dosis insulin sebanyak $27,1 \%$ sedangkan yang tidak sesuai sebanyak 72,9\%. Pada saat mengevaluasi guideline 2 berdasarkan kadar gula darah. Skala dosis pemberian insulin pada guideline 2 yang berdasarkan Update On Management Of In-hospital Hyperglycemia dapat dilihat pada Tabel XII.

Tabel XII. Skala insulin

\begin{tabular}{cccc}
\hline \multirow{2}{*}{ Kadar gula darah } & \multicolumn{3}{c}{ Guideline 2* } \\
\cline { 2 - 4 } & 2 & Skala insulin \\
\hline $141-180$ & 4 & 4 & 6 \\
$181-220$ & 6 & 6 & 8 \\
$221-260$ & 8 & 8 & 10 \\
$261-300$ & 10 & 10 & 12 \\
$301-350$ & 12 & 12 & 14 \\
$350-400$ & 14 & 16 & 16 \\
$>400$ & & & 18
\end{tabular}

*Update On Management Of In-hospital Hyperglycemia

Besarnya ketidaksesuaian dosis pada guideline 1 dan guideline 2 kemungkinan disebabkan karena penyakit diabetes melitusnya cukup kronis sehingga dalam pemberiannya membutuhkan dosis yang lebih tinggi. Pada terapi insulin tunggal maupun kombinasi disesuaikan dengan kondisi tubuh dalammerespon insulin. Dosis 
yang tidak sesuai dapat mengakibatkan penurunan toleransi glukosa yang mengakibatkan hiperglikemik berkepanjangan (Oktaviani, 2017). Faktor lain yang berpengaruh pada penurunan kadar gula darah selain ketidaksesuaiandosis yaitu pola makan. Pola makan responden diabetes melitus harus diperhatikan baik jadwal, jumlah maupun jenis makanannya (Imeida, 2019).

\section{KESIMPULAN}

Menurut literature Standard of Medical Care In Diabetes 2018, Drug Information Handbook 19th Edition (Lacy dkk, 2010), The Renal Drug Handbook, MIMS edisi 17, ISO volume 51 sebanyak $100 \%$ dengan kategori sesuai. Dosis insulin menurut guideline Comparison of 2 intravenous insulin protocols : glycemia variability in critically ill patientssebanyak $34,1 \%$ sesuai dan guidelineUpdate On Management Of In-hospital Hyperglycemia sebanyak $27,1 \%$ sesuai.

\section{UCAPAN TERIMAKASIH}

Ucapan terimakasih peneliti kepada Direktur dan Staff Rumah Sakit X.

\section{DAFTAR PUSTAKA}

Almasdy, D. Et Al., 2015. Evaluasi Penggunaan Obat Antidiabetik Pada Pasien Diabetes Melitus Tipe 2 Di Suatu Rumah Sakit Pemerintah Kota PadangSumatera Barat. Jurnal Sains Farmasi \& Klinis, Volume 2, Pp. 104-110.

Anonim, 2017. Mims Petunjuk Konsultasi. 17 Ed. Jakarta: Pt Medidata Indonesia.

Anonim, 2018. Standards Of Medical Care In Diabetes. S.L.:American Diabetes Association.

Ashley, C. \& Currie, A., 2009. The Renal Drug Handbook. New Zealand: Pindar Zn.

Garrido, G. M. Et Al., 2017. Comparison Of 2 Intravenous Insulin Protocols Glycemia Variability In Critically Ill Patient. Volume 64, Pp. 250-257.

Hongdiyanto, A., Yamlean, P. V. \& Supriati, H. S., 2014. Evaluasi Kerasionalan Pengobatan Diabetes Melitus Tipe 2 Pada Pasien Rawat Inap Di Rsup Prof. Dr. R. D. Kandao Manado Tahun 2013. Jurnal Ilmiah Farmasi-Unsrat, Volume 3, Pp. 77-86.

Imeida, S., 2019. Faktor-Faktor Yang Mempengaruhi Terjadinya Diabetes Melitus Di Puskesmas Harapan Raya Tahun 2018. Scientia Journal, Volume 8.

Jay, T. H. \& Rahardja, K., 2015. Obat-Obat Penting Khasiat, Penggunaan Dan Efek-Efek Sampingnya. Jakarta: Pt Elex Komputindo.

Kurnianto, D., 2015. Menjaga Kesehatan Di Usia Lanjut. Jurnal Olah Raga dan Prestasi , Volume 11.

Muthoharoh, A., Safitri, A. W., Pambudi, B. D. \& Rahman, F., 2020. Pola Pengobatan Antidiabetik Oral Pada Pasien Diabetes Melilitus Tipe 2 Rawat Jalan Di RSUD Kajen Pekalongan. Jurnal Farmasi Indonesian .

Notoatmodjo, S., 2010. Metodologi Penelitian Kesehatan. Jakarta: Pt Rineka Cipta. 
Oktaviani, E., Wahyono, D. \& Probosuseno, 2017. Evaluasi Penggunaan Antidiabetik Oral Pada Pasien Dm Tipe 2 Dengan Gangguan Fungsi Ginjal Rawat Jalan Di Rsup Dr Sardjito Yogyakarta Indonesia. Pp. 1-6.

Pallivalappil, B., Supreeth, N. R., Avinash, S. \& Imandi, H., 2017. Update On Management Of In-Hospital Hyperglycemia. Bmh Medical Journal, Volume 4, Pp. 91-98.

Purnamasari, L., 2017. Faktor Resiko, Klasifikasi Dan Terapi Sindrom Dispepsia. Volume 44.

Samoh, W., 2014. Evaluasi Ketetapan Obat Dan Dosis Pada Pasien Diabetes Mellitus Tipe 2 Dengan Komplikasi Hipertensi Di Rumah Sakit "X" Surakarta Periode Januari-April 2014. In: . Surakarta: Fakultas Farmasi Universitas Muhammadiyah , Pp. 1-16.

Sepmawati, D., 2014. Evaluasi Ketepatan Terapi Pada Pasien Diabetes Mellitus Tipe 2 Di Instalasi Rawat Inap Rs "A" Periode Januari - Juni 2015. In: Skripsi. Surakarta: Fakultas Farmasi Universitas Muhammadiyah.

Syuadzah, R., Wijayanti, L. \& Prasetyawati, E. A., 2017. Tingkat Kepatuhan Mengikuti Kegiatan Prolanis Pada Pasien Diabetes Melitus Tipe 2 Dengan Kadar Hbalc. Nexus Kedokteran Komunitas, P. 6.

Winarti \& Supriyanto, S., 2013. Analisis Kelengkapan Pengisian Dan Pengembalian Rekam Medik Rawat Inap Rumah Sakit. Jurnal Administrasi Kesehatan Indonesia, Volume 1. 